\title{
The Link Between Childhood Exposure to Violence and Academic Achievement: Complex Pathways
}

\author{
Tracy Vaillancourt • Patricia McDougall
}

Published online: 8 September 2013

(C) Springer Science+Business Media New York 2013

Exposure to violence, which includes peer victimization (i.e., bullying), family violence (i.e., child maltreatment and witnessing intimate partner abuse), and community violence (e.g., being physically assaulted, witnessing gunfire, etc.), is a pressing global public health issue that affects far too many children and youth who experience violence directly, or as witnesses, in their schools, homes, and communities. For example, a recent study examining national estimates of exposure to multiple types of violence among American children aged 0 to 17 years of age, indicated that over $60 \%$ had been exposed to violence and that $10 \%$ had experienced an injury as a result of their victimization (Finkelhor et al. 2009).

Studies on the negative effects of exposure to violence suggest that it interferes in a substantial way with healthy development. Exposure to violence in childhood and adolescence is strongly linked to internalizing and externalizing problems across all forms of abuse (see meta-analyses by Fowler et al. 2009; Hawker and Boulton 2000; Paolucci et al. 2001; Reijntjes et al. 2010; Reijntjes et al. 2011; Wolfe et al. 2003). What is particularly alarming about this literature is that the negative effects tend to persist into adulthood (e.g., Wolke et al. 2013), and confer risks beyond mental health problems. Indeed, recent studies on the neurobiology of victimization suggest that the experience of being abused can become biologically embedded in the physiology of the developing person, placing him/her at risk for poor health and earlier death (see review by Vaillancourt et al. 2013b). For instance, growing evidence suggests that early

\footnotetext{
T. Vaillancourt $(\triangle)$

Counselling, Faculty of Education and School of Psychology, Faculty of Social Sciences, University of Ottawa, Ottawa, Canada e-mail: tracy.vaillancourt@uottawa.ca

P. McDougall

Department of Psychology, University of Saskatchewan,

Saskatoon, Canada

e-mail: patti.mcdougall@usask.ca
}

adversity, which includes exposure to violence, is associated with changes to the DNA methylation. This epigenetic process is in turn implicated in how the individual responds to future stresses and/or whether or not he/she becomes ill (see Bick et al. 2012; Vaillancourt et al. 2013b for reviews).

It is clear from the extant literature that exposure to violence poses a significant health risk to children and youth. Accordingly, it seems intuitive that a direct relationship would similarly exist between exposure to violence and poorer academic outcomes (e.g., grade point average [GPA], school attendance, and school liking), given how stubbornly exposure to violence interferes with mental health functioning. In truth however, most researchers report small effect sizes or an inconsistent pattern of findings, especially with regard to peer victimization, which tends to show indirect associations, when associations are even found (Beran 2008; Hanish and Guerra 2002; Kochenderfer and Ladd 1996).

Perhaps the inconsistent link between exposure to violence and poor academic functioning should be expected in that there are "multiple contributors to adaptive or maladaptive outcomes in any individual", which may vary among individuals in terms of their relative contribution or in terms of their developmental course (Cicchetti and Rogosch 1996, p. 597). Additionally, perhaps the key to understanding complex associations between exposure and academic outcomes is to focus on processes and mechanisms rather than simple bivariate concurrent or short-term longitudinal associations. In this special section on violence exposure and academic achievement, studies that identify some of the mechanisms underlying the complex link between exposure to violence and academic achievement are included.

In Lepore and Kliewer's (2013) study, a novel mediator, sleep disturbances, was examined vis-à-vis exposure to community violence and peer victimization in a short-term longitudinal study. Results indicated that for 7 th grade American youth, community violence was associated with lower GPA, both directly and indirectly, via sleep problems; whereas for peer victimized youth, lower GPA occurred only indirectly in a 
pathway through sleep disturbances. In Troop-Gordon and Kuntz's (2013) study, links between peer victimization and school adjustment were examined over a 2-year period among 3rd and 4th grade American children. Results call attention to the importance of teacher-child relationships as a moderator, especially for bullied children. Bullied children showed declines in school liking, but declines were mitigated when these children shared a close, low conflict relationship with their teachers. Furthermore, bullied children who experienced a poor teacherchild relationship were at clear risk, showing a pattern of lower academic functioning, in contrast to bullied peers whose performance appeared to be at least somewhat protected by having a solid connection to their teachers. In Vaillancourt, Brittain, McDougall and Duku's (2013a) study, a developmental cascade model linking childhood victimization, internalizing and externalizing problems, and academic achievement was examined in Canadian 5th graders followed to grade 8 (with archival data from grade 3 ). Results indicated many multifarious associations between exposure to violence and academic outcomes (GPA and school attendance) and mental health functioning. Two examples of the many pathways found were that (1) poor writing performance in Grade 3 predicted lower grades and greater peer victimization in Grade 5 and (2) lower GPA consistently predicted higher externalizing problems the following year (Grade 6 to 7 and Grade 7 to 8 ).

Taken together, the studies in this special section suggest that the relation between exposure to violence and academic achievement emerges as more complicated than its relation to mental health functioning. It may be that academic achievement is closely tied to a stable trait like intelligence, which is less vulnerable to disruption, and potentially protects children against the deleterious impact of exposure to violence. In their recent meta-analytic study on peer victimization and academic achievement, Nakamato and Schwartz (2010) suggested that perhaps a "third variable might account for the association between bullying by peers and academic difficulties" (p. 237) and recommended that more studies are needed on mediators. We agree. As one clear possibility, it could be that mental health issues mediate the link between exposure to violence and academic achievement, but this is just one example. The implication of not fully understanding which variables mediate (or moderate) the relation between exposure to violence and academic achievement, is that our efforts to design effective interventions will continue to be thwarted.

In summary, we are arguing that knowing about the mechanisms through which exposure to violence impacts academic functioning (mediators), and knowing about the conditions under which exposure to violence will have an impact on academic functioning (moderators), are the next steps to successful intervention. This will allow researchers and clinicians to focus attention on experiences and circumstances that are more proximal to critical outcomes.

\section{References}

Beran, T. (2008). Consequences of being bullied at school. In D. Pepler \& W. Craig (Eds.), Understanding and addressing bullying: an international perspective (pp. 44-66). Bloomington: Authorhouse.

Bick, J., Naymova, O., Hunter, S., Barbot, B., Lee, M., Luthar, S. S., Raefski, A., \& Grigorenko, E. L. (2012). Childhood adversity and DNA methylation of genes involved in the hypothalamus-pituitaryadrenal axis and immune system: Whole-genome and candidategene associations. Development and Psychopathology, 24, 14171425 .

Cicchetti, D., \& Rogosch, F. A. (1996). Equifinality and multifinality in developmental psychopathology. Development and Psychopathology, $8,597-600$.

Finkelhor, D., Turner, H., Ormrod, R., \& Hamby, S. L. (2009). Violence, abuse, and crime exposure in a national sample of children and youth. Pediatrics, 214, 1411-1423.

Fowler, P. J., Tompsett, C. J., Braciszewski, J. M., Jacques-Tiura, A. J., \& Baltes, B. B. (2009). Community violence: A meta-analysis on the effect of exposure and mental health outcomes of children and adolescents. Development and Psychopathology, 21, 227-259.

Hanish, L. D., \& Guerra, N. G. (2002). A longitudinal analysis of patterns of adjustment following peer victimization. Development and Psychopathology, 14, 69-89.

Hawker, D. S. J., \& Boulton, M. J. (2000). Twenty years' research on peer victimization and psychosocial maladjustment: A meta-analytic review of cross-sectional studies. Journal of Child Psychology and Psychiatry, 41, 441-455.

Kochenderfer, B. J., \& Ladd, G. W. (1996). Peer victimization: Cause or consequence of school maladjustment? Child Development, 67, $1305-1317$.

Lepore, S.L., \& Kliewer, W. (2013). Violence exposure, sleep disturbance, and poor academic performance in middle school. Journal of Abnormal Child Psychology. doi:10.1007/s10802-013-9709-0

Nakamoto, J., \& Schwartz, D. (2010). Is peer victimization associated with academic achievement? A meta-analytic review. Social Development, 19, 221-242.

Paolucci, E. O., Genuis, M., \& Violato, C. (2001). A meta-analysis of the published research on the effects of child sexual abuse. The Journal of Psychology, 135, 17-36.

Reijntjes, A., Kamphuis, J. H., Prinzie, P., \& Telch, M. J. (2010). Peer victimization and internalizing problems in children: a meta-analysis of longitudinal studies. Child Abuse \& Neglect, 34, 244.

Reijntjes, A., Kamphuis, J. H., Prinzie, P., Boelen, P. A., van der Schoot, M., \& Telch, M. J. (2011). Prospective linkages between peer victimization and externalizing problems in children: a meta-analysis. Aggressive Behavior, 37, 215-222.

Troop-Gordon, W. \& Kuntz, K.J. (2013). The unique and interactive contributions of peer victimization and teacher-child relationships to children's school adjustment. Journal of Abnormal Child Psychology. doi:10.1007/s10802-013-9776-2

Vaillancourt, T., Brittain, H., McDougall, P., \& Duku, E. (2013a). Longitudinal links between childhood peer victimization, internalizing and externalizing problems, and academic functioning: Developmental cascades. Journal of Abnormal Child Psychology, in press.

Vaillancourt, T., Hymel, S., \& McDougall, P. (2013b). The biological underpinnings of peer victimization: Understanding why and how the effects of bullying can last a lifetime. Theory into Practice, in press.

Wolfe, D. A., Crooks, C. V., Lee, V., McIntyre-Smith, A., \& Jaffe, P. G. (2003). The effects of children's exposure to domestic violence: A meta-analysis and critique. Clinical Child and Family Psychology Review, 6, 171-187.

Wolke, D., Copeland, W.E., Angold, A., \& Costello, E.J. (2013). Impact of bullying in childhood on adult health, wealth, crime, and social outcomes. Psychological Science. doi:10.1177/0956797613481608 